\title{
Caracterização geoquímica com indícios paleoambientais de folhelhos da Formação Pimenteiras, estado do Tocantins, Bacia do Parnaíba, Brasil
}

\author{
Geochemical characterization with paleoenvironment clues of shales \\ from Pimenteiras Formation, Tocantins State, Parnaíba Basin, Brazil
}

\begin{abstract}
Eileen Rocío Niño Zambrano ${ }^{1}$,Olívia Maria Cordeiro de Oliveira ${ }^{1}$, Hélio Jorge Portugal Severiano Ribeiro ${ }^{2}$ ${ }^{1}$ Programa de Pós-graduação em Geoquímica: Petróleo e Meio Ambiente, Instituto de Geociências, Universidade Federal da Bahia - UFBA, Avenida Adhemar de Barros, s/n, CEP 40170-110, Salvador, BA, BR (eironiza84@gmail.com; olivia@ufba.br) ${ }^{2}$ Programa de Pós-graduação do Laboratório de Engenharia e Exploração de Petróleo, Centro de Ciência e Tecnologia, Universidade Estadual do Norte Fluminense Darcy Ribeiro - UENF (severian@lenep.uenf.br)
\end{abstract}

Recebido em 16 de março de 2016; aceito em 28 de abril de 2017

\begin{abstract}
Resumo
A descoberta de gás natural em depósitos siliciclásticos da Bacia do Parnaíba impulsionou novas pesquisas no intuito de entender o sistema petrolífero, caracterizar intervalos de rocha com potencial gerador de hidrocarbonetos, bem como melhorar a caracterização paleoambiental. Visto que a deposição da principal rocha geradora na Bacia do Parnaíba, a Formação Pimenteiras, ocorreu durante o Devoniano, associada a um evento anóxico global no Frasniano, amostras de folhelhos devonianos foram coletadas em afloramentos da Formação Pimenteiras e analisadas por meio das técnicas geoquímicas de carbono orgânico total, enxofre total, pirólise Rock Eval e isótopos estáveis de carbono. Os resultados obtidos das análises nas 27 amostras de rocha geradora coletadas indicaram que $67 \%$ das amostras possuem o teor de carbono orgânico total mínimo requerido para gerar hidrocarbonetos. Cerca de $77 \%$ das amostras apresentaram potencial para gerar gás, enquanto os percentuais restantes são os correspondentes às amostras com potencial de gerar óleo ou gás. A temperatura máxima de pirólise sugere imaturidade termal das amostras. A correlação dos dados geoquímicos permitiu reconhecer indícios das variações no paleoambiente deposicional dos afloramentos estudados, provavelmente por inundações marinhas.
\end{abstract}

Palavras-chave: Formação Pimenteiras; Bacia do Parnaíba; Rochas geradoras; Devoniano; Geoquímica orgânica.

\begin{abstract}
The discovery of natural gas in siliciclastic deposits of the Parnaíba Basin has motived new research to understand the petroleum system, to characterize source rock intervals, as well as to improve the paleoenvironmental characterization. Since the deposition of the main source rock in the Parnaíba Basin, the Pimenteiras Formation, occurred during the Devonian, associated with global anoxic event at the Fransnian, shales samples of Devonian were collected from outcrops of Pimenteiras Formation and analyzed using the geochemical techniques of total organic carbon, total sulfur, Rock Eval pyrolysis and stable carbon isotopes. Analysis results of 27 source rock samples indicated that $67 \%$ of the samples have a minimum total organic carbon content required to produce hydrocarbons. Approximately $77 \%$ of the samples had the potential to generate gas, while the remaining percentage are those corresponding to the samples with the potential to generate oil or gas. The maximum pyrolysis temperature suggests thermal immaturity of the samples. The geochemical data correlation allowed recognizing signs of changes in the depositional paleoenvironment of the outcrops studied, probably by sea flooding.
\end{abstract}

Keywords: Pimenteiras Formation; Parnaíba Basin; Source rocks; Devonian; Organic geochemical. 


\section{INTRODUÇÃO}

A Bacia do Parnaíba está situada na região nordeste ocidental brasileira, com uma área de cerca de $665.888 \mathrm{~km}^{2}$, abrangendo a quase totalidade dos estados do Maranhão e do Piauí e pequenas faixas do Pará, Ceará, Tocantins, Goiás e Bahia. A atividade exploratória da bacia voltada para a pesquisa de hidrocarbonetos data dos anos 1950. Como resultado dessas atividades, quatro campos de gás natural foram descobertos em 2010, 2011 e 2012 com reservas de gás. Esses depósitos de gás natural, cuja rocha geradora é constituída pelos folhelhos da Formação Pimenteiras, impulsionou novas pesquisas no intuito de entender o sistema petrolífero, que incluem a caracterização paleoambiental. Atualmente, a Bacia do Parnaíba encontra-se em um estágio exploratório com expectativas de ocorrência de petróleo (Araújo, 2015). De acordo com Menezes et al. (2008), a utilização e a interpretação dos resultados analíticos de geoquímica orgânica de rochas geradoras de hidrocarbonetos compreendem uma das etapas mais importantes para o sucesso da exploração petrolífera.

Estudos geoquímicos anteriores realizados na Bacia do Parnaíba identificaram três intervalos potencialmente geradores dentro da Formação Pimenteiras, denominados de folhelhos radioativos A, B e C (Rodrigues, 1995). Os folhelhos radioativos $\mathrm{A}$, reportados com índices de carbono orgânico total (COT) variando entre 1,0 e 3,0\%, com matéria orgânica do tipo III, são os únicos que se encontram maturos por subsidência na porção NO da bacia. Os folhelhos radioativos B possuem COT variando entre 1,0 e 3,5\% e matéria orgânica dos tipos II e III. Enquanto os folhelhos radiativos C possuem COT variando entre 1,0 e 5,0\% e matéria orgânica do tipo II, sendo o principal intervalo de folhelhos radioativos.

O presente trabalho enfoca a caracterização geoquímica de rochas geradoras quanto ao potencial gerador de hidrocarbonetos, assim como indícios do paleoambiente deposicional sob o ponto de vista da geoquímica orgânica, nas amostras de rochas coletadas em afloramentos da Formação Pimenteiras (Devoniano), na borda oeste da Bacia do Parnaíba, estado do Tocantins.

\section{CONTEXTO GEOLÓGICO}

A Bacia do Parnaíba é uma bacia paleozoica intracratônica que se encontra limitada ao norte pelo Arco Ferrer-Urbano Santos, a leste pela Falha de Tauá, a sudeste pelo Lineamento Senador Pompeu, a oeste pelo Lineamento Tocantins-Araguaia e a noroeste pelo Arco Tocantins (Bizzi et al., 2003).

O registro sedimentar da Bacia do Parnaíba apresenta-se com espessura máxima de $3.500 \mathrm{~m}$, compreendendo rochas siliciclásticas, calcários, anidritas, sílex, além de diabásio e basalto de idade jurocretácea (Vaz et al., 2007).
O arcabouço estratigráfico da Bacia do Parnaíba é dividido em cinco supersequências: Siluriana, MesodevonianaEocarbonífera, Neocarbonífera-Eotriássica, Jurássica e Cretácea (Figura 1). No contexto da Plataforma SulAmericana, as três primeiras sequências paleozoicas encontram-se no estágio de estabilização e são delimitadas por discordâncias relacionadas às flutuações dos elevados níveis eustáticos dos mares epicontinentais do Eopaleozoico (Almeida e Carneiro, 2004; Vaz et al., 2007). As transgressões procederam do oceano adjacente à margem ativa do sudoeste do Gondwana e de bacias do norte atual da África, inundadas pelo Oceano Tethys. As regressões e discordâncias erosivas teriam contribuições de ascensões epirogênicas, em resposta às orogêneses ocorridas na borda ativa do Gondwana adjacente à plataforma (Vaz et al., 2007).

As inundações marinhas mais extensas correspondem ao Fanerozoico da América do Sul, registradas no Devoniano. O evento de inundações ocorrido no período referido na Bacia do Parnaíba iniciou com um ciclo transgressivo/regressivo de idades Eoefeliana e Eogivetiana, que compreende a Formação Itaim, a parte basal e média da Formação Pimenteiras e a parte inferior da Formação Cabeças. Nas porções superiores da Formação Pimenteiras e da Formação Cabeças ocorre uma nova transgressão no Neofrasniano-Eofameniano (Santos e Carvalho, 2009). Durante essa idade, na Formação Pimenteiras ocorrem folhelhos pretos, radioativos, ricos em matéria orgânica, segundo Rodrigues (1995).

A Formação Pimenteiras está composta por camadas $(10$ a $30 \mathrm{~m})$ de folhelhos cinza-escuros a pretos com intercalações de lâminas de arenito muito fino (Della Fávera, 1990). Seus estratos apresentam uma tendência granodecrescente ascendente cíclica, interpretados como a mais importante incursão marinha na bacia. O topo dos ciclos é reconhecido pela presença de corpos de arenitos de 3 a $5 \mathrm{~m}$ de espessura e de extensão de até $100 \mathrm{~m}$, com geometria de lobos ou barras, com estratificação cruzada tipo hummocky, e hardgrounds bioturbados. As feições grafoelétricas indicam ciclicidade deposicional, e uma mudança de tendência transgressiva para regressiva na passagem gradacional para a Formação Cabeças, que lhe é sobreposta (Della Fávera, 1990). Interpretações paleoambientais indicam plataforma rasa dominada por tempestades (Della Fávera, 1990) e correntes de maré (Silva, 2005; Amaral et al., 2013), além da influência de um sistema deltaico, segundo Carozzi et al. (1975), Della Fávera (2001) e Della Fávera et al. (2003).

\section{MATERIAIS E MÉTODOS}

\section{Área de estudo}

A área de estudo corresponde a uma faixa de afloramentos da Formação Pimenteiras (Devoniano) no centro-norte do 
estado de Tocantins. Os afloramentos escolhidos para a coleta de rochas foram selecionados dos principais intervalos ricos em matéria orgânica referenciados em Parra (2012). Um total de 27 amostras de folhelhos foi coletado de forma sequencial a cada metro de altura, aproximadamente, dentro de dois afloramentos da Formação Pimenteiras, na borda oeste da Bacia do Parnaíba, estado de Tocantins, Brasil (Tabela 1 e Figura 2).

No afloramento FP-3 foram coletadas 16 amostras de rocha, e no afloramento FP-6,11 amostras. A fim de facilitar a identificação, a partir da coloração cinza clara, média e escura dos folhelhos, foram diferenciados os afloramentos por terços: o terço inferior correspondente à base do afloramento, onde iniciou a coleta das amostras; o terço médio é composto pelas amostras coletadas entre 4 e $9 \mathrm{~m}$ para o afloramento FP-3, e entre 4 e $7 \mathrm{~m}$ para o FP-6, medidos a partir da base; o terço superior é composto pelas amostras localizadas no topo do afloramento (Figura 3). Além disso, as amostras foram identificadas por números, dos quais o primeiro refere-se ao afloramento e o seguinte à altura de coleta (exemplo: a amostra 3.11 pertence ao afloramento FP-3 e foi coletado a 11 metros de altura medidos desde a base do afloramento).
O afloramento FP-3 foi composto por folhelhos cinza-claros no terço inferior, folhelhos cinza-claros a escuros no terço médio e folhelhos predominantemente escuros no terço superior com intercalações cinza-claras até a primeira metade terço, destacando-se camadas milimétricas de areia intercaladas com folhelho na amostra 3.10 (Figura 3A). A caracterização litológica do afloramento FP-6 encontra-se na Figura 3B, o qual foi constituído no

Tabela 1. Localização geográfica dos afloramentos, nos quais foi realizada a coleta das amostras de rochas.

\begin{tabular}{|c|c|}
\hline Afloramento FP-3 & Afloramento FP-6 \\
\hline $\begin{array}{l}\text { Localização: margem } \\
\text { sudeste do km } 29 \text { da } \\
\text { rodovia TO-010 (Bom Jesus } \\
\text { do Tocantins-Santa Maria } \\
\text { do Tocantins) } \\
\text { Coordenadas geográficas*: } \\
8^{\circ} 53^{\prime} 20,0 " \\
47^{\circ} 57^{\prime} 35,6 " \\
\text { Coleta: } 16 \text { amostras de } \\
\text { folhelho }\end{array}$ & $\begin{array}{c}\text { Localização: margem oeste } \\
\text { do km } 399 \text { da rodovia BR- } \\
153 \text { (Belém-Brasília) } \\
\text { Coordenadas geográficas*: } \\
9^{\circ} 25^{\prime} \text { '22,3" } \\
48^{\circ} 34^{\prime} 20,5^{\prime \prime} \\
\text { Coleta: } 11 \text { amostras de } \\
\text { folhelho }\end{array}$ \\
\hline
\end{tabular}

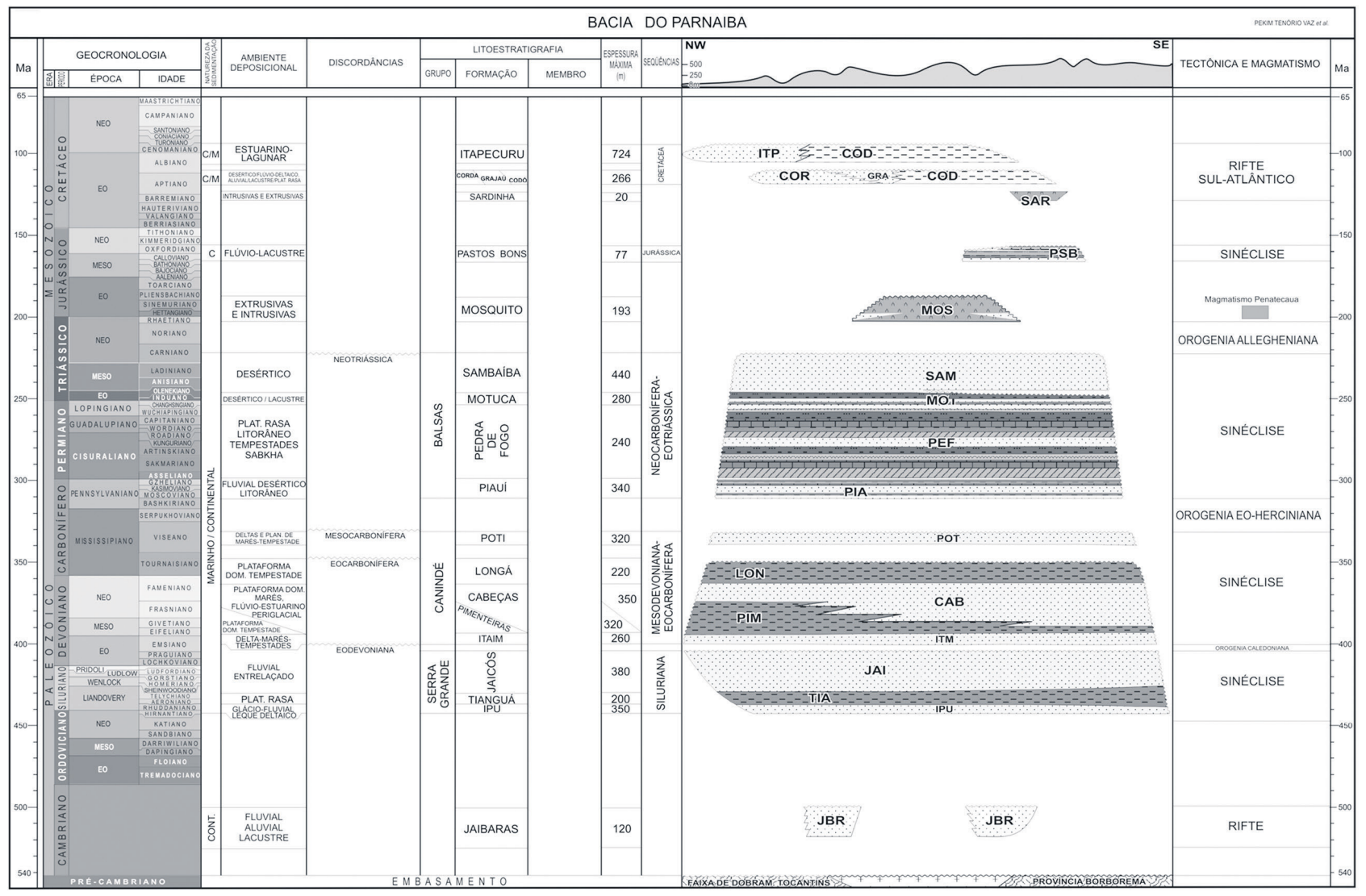

Figura 1. Carta estratigráfica da Bacia do Parnaíba (Vaz et al., 2007). 
terço inferior por folhelhos cinza-claros, no terço médio por folhelhos cinza-claros com intercalações cinza-escuras, e no terço superior por folhelhos cinza-escuros com intercalações cinza-claras. É importante destacar a coloração amarela, indicador da presença de enxofre em todos os folhelhos dos afloramentos FP-3 e FP-6, com maior predominância no terço superior.

\section{Métodos analíticos}

Inicialmente as amostras de rocha foram maceradas até serem reduzidas ao tamanho de 80 mesh $(0,177 \mathrm{~mm})$. $\mathrm{Na}$ análise elementar de carbono orgânico total (COT) e composição isotópica, as amostras pulverizadas foram tratadas usando ácido clorídrico $6 \mathrm{~N}$ para remover os carbonatos e, após esse procedimento, as amostras foram lavadas com água deionizada por 4 horas. Os resíduos insolúveis foram levados à combustão $\left(950^{\circ} \mathrm{C}\right)$ num analisador elementar da marca LECO $628 \mathrm{CN}$, do Laboratório de Estudos do Petróleo (LEPETRO) da Universidade Federal da Bahia (UFBA). Esse equipamento possui um detector infravermelho que determina a quantidade de COT contido na amostra, em valores $\%$ em peso. Para avaliar a quantidade de enxofre total foi usado o LECO $628 \mathrm{~S}$, com detector de ionização de chama (FID).

A pirólise Rock Eval foi realizada para as amostras com o conteúdo de COT $>0,80 \%$. Entre 60 e $80 \mathrm{mg}$ de amostra de rochas pulverizadas foram aquecidas de 300 até $600^{\circ} \mathrm{C}$ a $25^{\circ} \mathrm{C} / \mathrm{min}$. em atmosfera de nitrogênio, empregando-se um analisador Rock Eval 6 do LEPETRO da UFBA. Os resultados evidenciaram os hidrocarbonetos livres contidos na rocha $\left(\mathrm{S}_{1}\right)$, o potencial gerador de hidrocarbonetos $\left(\mathrm{S}_{2}\right)$ e a temperatura máxima de pirólise (Tmáx.) em que ocorre o craqueamento do querogênio (Tissot e Welte, 1984).

As composições isotópicas estáveis de carbono expressas em notação delta por mil nas rochas foram analisadas no espectrômetro de massas acoplado com cromatografia gasosa PDZ-Europa, modelo GLS 20-20, no Laboratório de Isótopos Estáveis do Centro de Energia Nuclear na Agricultura da Universidade de São Paulo (CENA/USP). A notação $\delta$ (delta) é usada para expressar as razões dos isótopos ${ }^{13} \mathrm{C} /{ }^{12} \mathrm{C}$. Os dados são apresentados com o desvio do padrão internacional Pee Dee Belemnite (PDB), o qual se refere ao belemnite fóssil (carbonato) da Formação Pee Dee, do Cretáceo, localizada na Carolina do Sul, EUA.

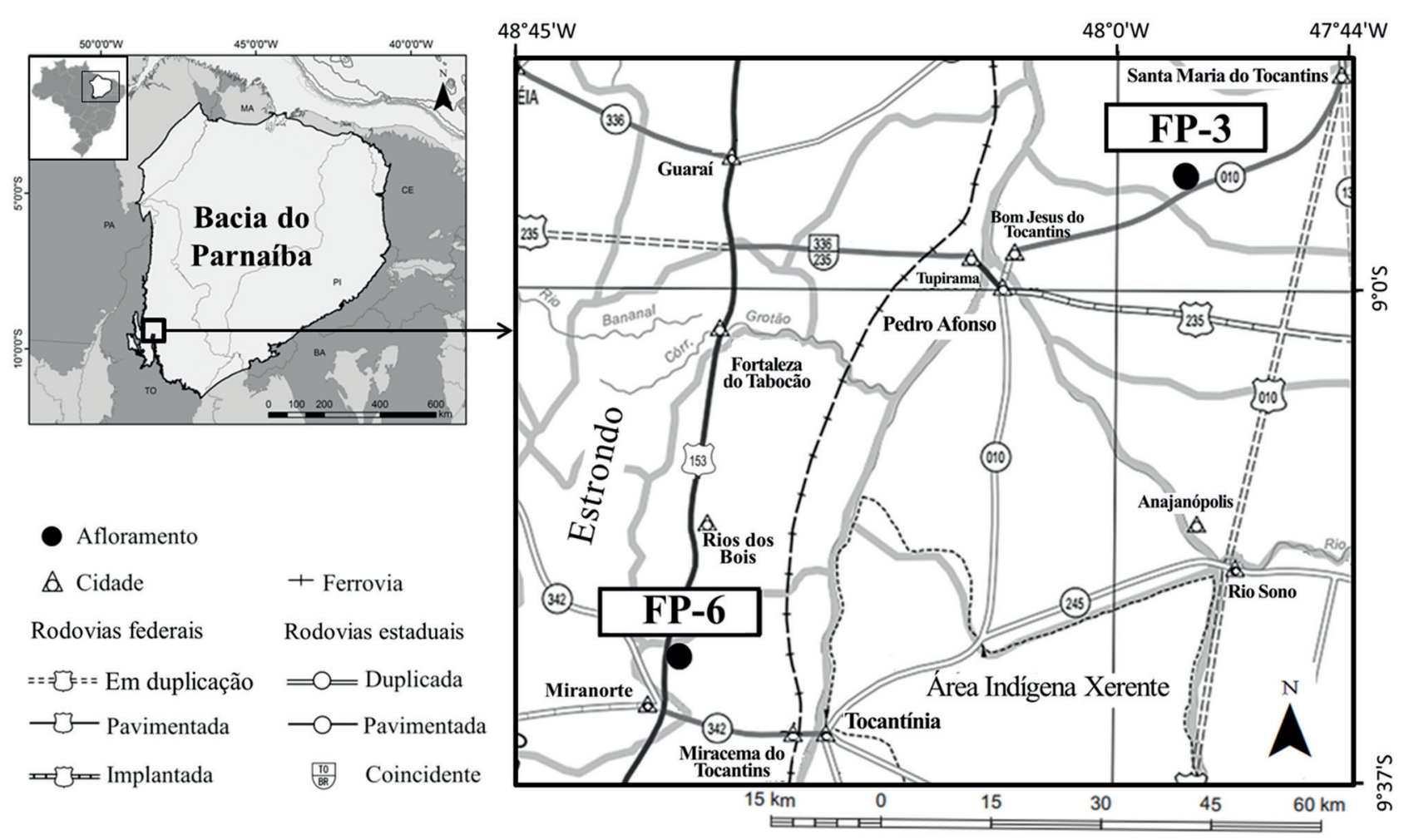

Figura 2. Localização geográfica dos afloramentos FP-3 - localizado no km 29 da rodovia TO-010 (Bom Jesus do Tocantins-Santa Maria do Tocantins) - e FP-6 - localizado no km 399 da rodovia BR-153 (Belém-Brasília). 
Essa notação é definida pela Equação 1:

$\delta=\left(\frac{R a-R p}{R p}\right) * 10^{3}$

Onde:

$\mathrm{Ra}$ e $\mathrm{Rp}$ referem-se à razão isotópica;

${ }^{13} \mathrm{C} /{ }^{12} \mathrm{C}$ da amostra e do padrão, respectivamente.

\section{RESULTADOS E DISCUSSÕES}

Os resultados das análises elementares de COT, enxofre total, análises de isótopos de carbono e pirólise Rock Eval são apresentados na Tabela 2 .

\section{Quantidade da matéria orgânica e enxofre total}

Os valores de COT nas amostras do afloramento FP-3 variaram entre 0,12 e 3,72\%, com valores mais elevados de
1,20 até $3,72 \%$ no intervalo do terço médio até o superior (amostras 3.4 a 3.16), exceto a amostra 3.12 (0,78\% COT). Cerca de $81 \%$ das amostras de FP-3 evidenciaram a quantidade mínima ( $>1 \%$ em peso) de COT aceita para que uma rocha sedimentar siliciclástica possa ser considerada como possível rocha geradora de hidrocarbonetos.

Entretanto, as amostras de FP-6 apresentaram valores de COT entre 0,32 e 3,12\% em peso (Tabela 2). Foi possível observar valores de COT mais elevados entre 2,67 e $3,12 \%$ para as amostras coletadas no terço superior do afloramento FP-6 (amostras 6.8 a 6.11). Cerca de $46 \%$ das amostras $(6.2,6.8,6.9,6.10$ e 6.11$)$ atingiram valores maiores que $1,00 \%$, permitindo classificá-las como possíveis rochas geradoras.

Com relação aos teores de enxofre (Tabela 2), foi possível observar que os valores oscilaram de 0,14 a 2,94\% para as amostras de FP-3. Os máximos conteúdos de enxofre foram apresentados nas amostras 3.7 e 3.14, com valores de 2,20 e $2,94 \%$, respectivamente. Para o afloramento FP-6, os valores de enxofre oscilaram entre 0,05 e 1,40\%. Pode ser observado, para as amostras coletadas no terço
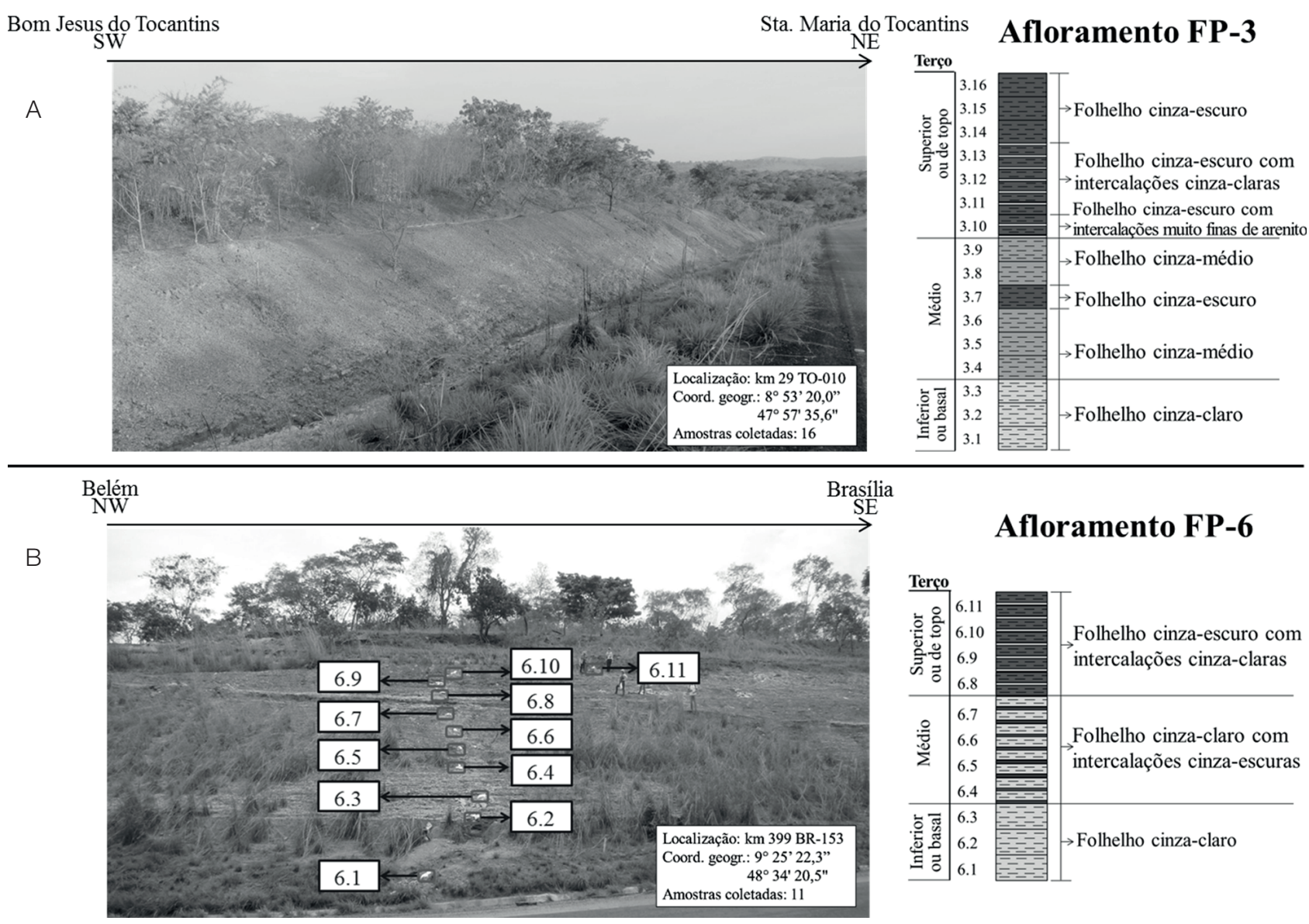

Figura 3. Amostras coletadas nos afloramentos (A) FP-3, localizado no km 29 da rodovia TO-010 (Bom Jesus do Tocantins-Santa Maria do Tocantins); e (B) FP-6, localizado no km 399 da rodovia BR-153 (Belém-Brasília). 
superior do afloramento $(6.8,6.9,6.10$ e 6.11$)$, um aumento no conteúdo de enxofre, com valores oscilando de 0,39 a $1,40 \%$. No mesmo terço foi verificado um elevado teor de COT, com valores entre 2,67 e $3,12 \%$.

No geral, foi observado que as amostras com valores maiores de porcentagem de enxofre tendem a apresentar valores elevados de COT para os afloramentos estudados. De acordo com Berner (1984), o enxofre incorporado nos sedimentos é devido à ação de bactérias redutoras de sulfato presentes na coluna de água livre de oxigênio sobre a matéria orgânica. Consequentemente, os valores elevados de enxofre são indicativos de deposição em ambientes anóxicos (Berner, 1984), sabendo-se que a preservação da matéria orgânica é maior nesses ambientes do que nos óxicos devido à redução da degradação de organismos aeróbicos. Portanto, altos valores de enxofre poderiam sugerir maior preservação da matéria orgânica para gerar hidrocarbonetos.

Alternativamente, o enxofre incorporado na matéria orgânica também pode ser derivado de enxofre elementar e de polissulfetos. Cabe salientar que uma porcentagem do enxofre no querogênio é derivada diretamente da biomassa

Tabela 2. Resultados obtidos das análises de carbono orgânico total, enxofre total, isótopos de carbono e pirólise Rock Eval das amostras de rocha dos afloramentos FP-3 e FP-6.

\begin{tabular}{|c|c|c|c|c|c|c|c|c|c|c|c|}
\hline \multirow{2}{*}{ Terço } & & \multirow[b]{2}{*}{ Amostras } & \multirow[b]{2}{*}{$\begin{array}{l}\text { COT } \\
(\%)\end{array}$} & \multirow[b]{2}{*}{$\begin{array}{c}\mathrm{S} \\
(\%)\end{array}$} & \multirow[b]{2}{*}{$\begin{array}{l}\delta^{13} \mathrm{C} \\
(\% \circ)\end{array}$} & \multicolumn{6}{|c|}{ Rock Eval } \\
\hline & & & & & & $\begin{array}{c}\mathrm{S}_{1} \\
\text { (mg HC/ } \\
\text { g rocha) }\end{array}$ & $\begin{array}{c}\mathrm{S}_{2} \\
\text { (mg HC/ } \\
\text { g rocha) }\end{array}$ & $\begin{array}{c}\mathrm{S}_{3} \\
\text { (mg CO} \\
\text { g rocha) }\end{array}$ & $\begin{array}{c}\text { Tmáx. } \\
\left({ }^{\circ} \mathrm{C}\right)\end{array}$ & $\begin{array}{c}\mathrm{IH} \\
\text { (mg HC/ } \\
\text { g COT) }\end{array}$ & $\begin{array}{c}\mathrm{IO} \\
(\mathrm{mg} \mathrm{CO} / \\
\mathrm{g} \mathrm{COT})\end{array}$ \\
\hline \multirow{16}{*}{ 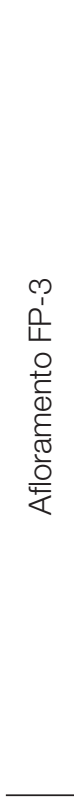 } & \multirow{7}{*}{$\begin{array}{l}\frac{1}{0} \\
\frac{0}{0} \\
\frac{0}{7} \\
\text { क }\end{array}$} & 3.16 & 2,35 & 1,46 & $-26,27$ & 0,06 & 3,73 & 0,69 & 426 & 159 & 28 \\
\hline & & 3.15 & 3,00 & 0,54 & $-26,11$ & 0,10 & 5,53 & 1,52 & 425 & 184 & 51 \\
\hline & & 3.14 & 3,72 & 2,94 & $-26,48$ & 0,09 & 5,31 & 0,85 & 422 & 143 & 23 \\
\hline & & 3.13 & 3,16 & 0,93 & $-26,58$ & 0,08 & 6,23 & 1,18 & 427 & 197 & 37 \\
\hline & & 3.12 & 0,78 & 0,83 & $-27,13$ & 0,01 & 0,78 & 0,22 & 426 & 100 & 28 \\
\hline & & 3.11 & 1,20 & 1,73 & $-27,12$ & 0,02 & 1,41 & 0,60 & 428 & 117 & 50 \\
\hline & & 3.10 & 3,35 & 1,04 & $-25,54$ & 0,09 & 6,86 & 1,60 & 427 & 205 & 48 \\
\hline & \multirow{6}{*}{$\begin{array}{l}\frac{0}{0} \\
\frac{0}{2}\end{array}$} & 3.9 & 2,28 & 0,78 & $-26,34$ & 0,05 & 2,53 & 1,82 & 425 & 111 & 80 \\
\hline & & 3.8 & 2,48 & 0,78 & $-26,61$ & 0,06 & 3,14 & 1,88 & 424 & 127 & 76 \\
\hline & & 3.7 & 3,04 & 2,20 & $-26,49$ & 0,06 & 6,48 & 0,69 & 428 & 213 & 23 \\
\hline & & 3.6 & 1,64 & 0,51 & $-26,40$ & 0,04 & 2,92 & 0,86 & 429 & 179 & 53 \\
\hline & & 3.5 & 2,92 & 0,33 & $-25,99$ & 0,07 & 7,28 & 1,30 & 432 & 249 & 45 \\
\hline & & 3.4 & 1,79 & 1,60 & $-27,86$ & 0,02 & 2,90 & 0,35 & 430 & 162 & 20 \\
\hline & \multirow{3}{*}{ 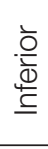 } & 3.3 & 0,36 & 0,14 & $-26,71$ & - & - & - & - & - & - \\
\hline & & 3.2 & 0,12 & 1,00 & $-26,96$ & - & - & - & - & - & - \\
\hline & & 3.1 & 1,11 & 0,70 & $-27,49$ & 0,03 & 1,11 & 0,37 & 424 & 100 & 33 \\
\hline \multirow{11}{*}{ 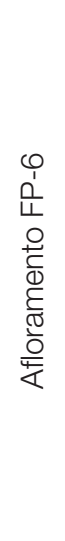 } & \multirow{4}{*}{ 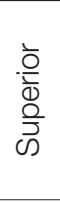 } & 6.11 & 2,67 & 0,48 & $-25,84$ & 0,06 & 6,75 & 1,91 & 430 & 252 & 71 \\
\hline & & 6.10 & 3,12 & 0,39 & $-25,68$ & 0,09 & 8,34 & 1,90 & 430 & 267 & 61 \\
\hline & & 6.9 & 2,93 & 1,40 & $-25,88$ & 0,07 & 5,34 & 1,16 & 429 & 187 & 40 \\
\hline & & 6.8 & 3,08 & 1,01 & $-26,23$ & 0,08 & 5,46 & 1,79 & 426 & 177 & 58 \\
\hline & \multirow{4}{*}{$\begin{array}{l}\frac{.0}{0} \\
\stackrel{\oplus}{\Sigma}\end{array}$} & 6.7 & 0,77 & 0,18 & $-26,64$ & 0,01 & 0,95 & 0,41 & 434 & 124 & 53 \\
\hline & & 6.6 & 0,85 & 0,06 & $-26,77$ & 0,01 & 0,93 & 0,68 & 434 & 110 & 80 \\
\hline & & 6.5 & 0,66 & 0,05 & $-26,48$ & - & - & - & - & - & - \\
\hline & & 6.4 & 0,60 & 0,07 & $-26,66$ & - & - & - & - & - & - \\
\hline & \multirow{3}{*}{$\begin{array}{l}\frac{1}{\frac{1}{Q}} \\
\stackrel{\underline{D}}{=} \\
.\end{array}$} & 6.3 & 0,32 & 0,06 & $-26,21$ & - & - & - & - & - & - \\
\hline & & 6.2 & 1,07 & 0,06 & $-26,89$ & 0,01 & 1,68 & 0,50 & 438 & 157 & 47 \\
\hline & & 6.1 & 0,98 & 0,09 & $-26,82$ & 0,01 & 1,08 & 0,68 & 436 & 110 & 69 \\
\hline
\end{tabular}

COT: carbono orgânico total (\%); S: enxofre total (\%); $\delta^{13} \mathrm{C}$ : composição de isótopos estáveis de carbono ${ }^{13} \mathrm{C} /{ }^{12} \mathrm{C}(\%)$; S: hidrocarbonetos livres contidos na rocha ( $\mathrm{mg} \mathrm{HC} / \mathrm{g}$ rocha); $\mathrm{S}_{2}$ :potencial gerador de hidrocarbonetos ( $\mathrm{mg} \mathrm{HC} / \mathrm{g}$ rocha); $\mathrm{S}_{3}$ : conteúdo de dióxido de carbono (mg $\mathrm{CO}_{2} / \mathrm{g}$ rocha); Tmáx.: temperatura máxima de pirólise ( $\left.{ }^{\circ} \mathrm{C}\right)$; $1 \mathrm{H}$ : índice de hidrogênio ( $\mathrm{mg} \mathrm{HC} / \mathrm{g} \mathrm{COT}$ ); IO: índice de oxigênio ( $\mathrm{mg} \mathrm{CO}_{2} / \mathrm{g} \mathrm{COT);} \mathrm{(-)} \mathrm{não} \mathrm{foi} \mathrm{realizada} \mathrm{a} \mathrm{análise} \mathrm{nessa} \mathrm{amostra.}$ 
da qual se formou, proveniente de moléculas como aminoácidos e proteínas de algas e bactérias (Werne et al., 2003).

\section{Qualidade da matéria orgânica}

Com base nos intervalos propostos por Peters e Cassa (1994), ilustrados por diferentes cores conforme Figura 4, foi possível observar as variações dos parâmetros geoquímicos do COT, do potencial gerador $\left(\mathrm{S}_{2}\right)$, do índice de hidrogênio (IH) e da Tmáx. para as amostras dos afloramentos FP-3 e FP-6.

Cerca de 56\% das amostras de FP-3 (amostra 3.5 e intervalos 3.7 a 3.10 e 3.13 a 3.16 ) apresentaram teores de carbono orgânico classificados como "muito bom" para

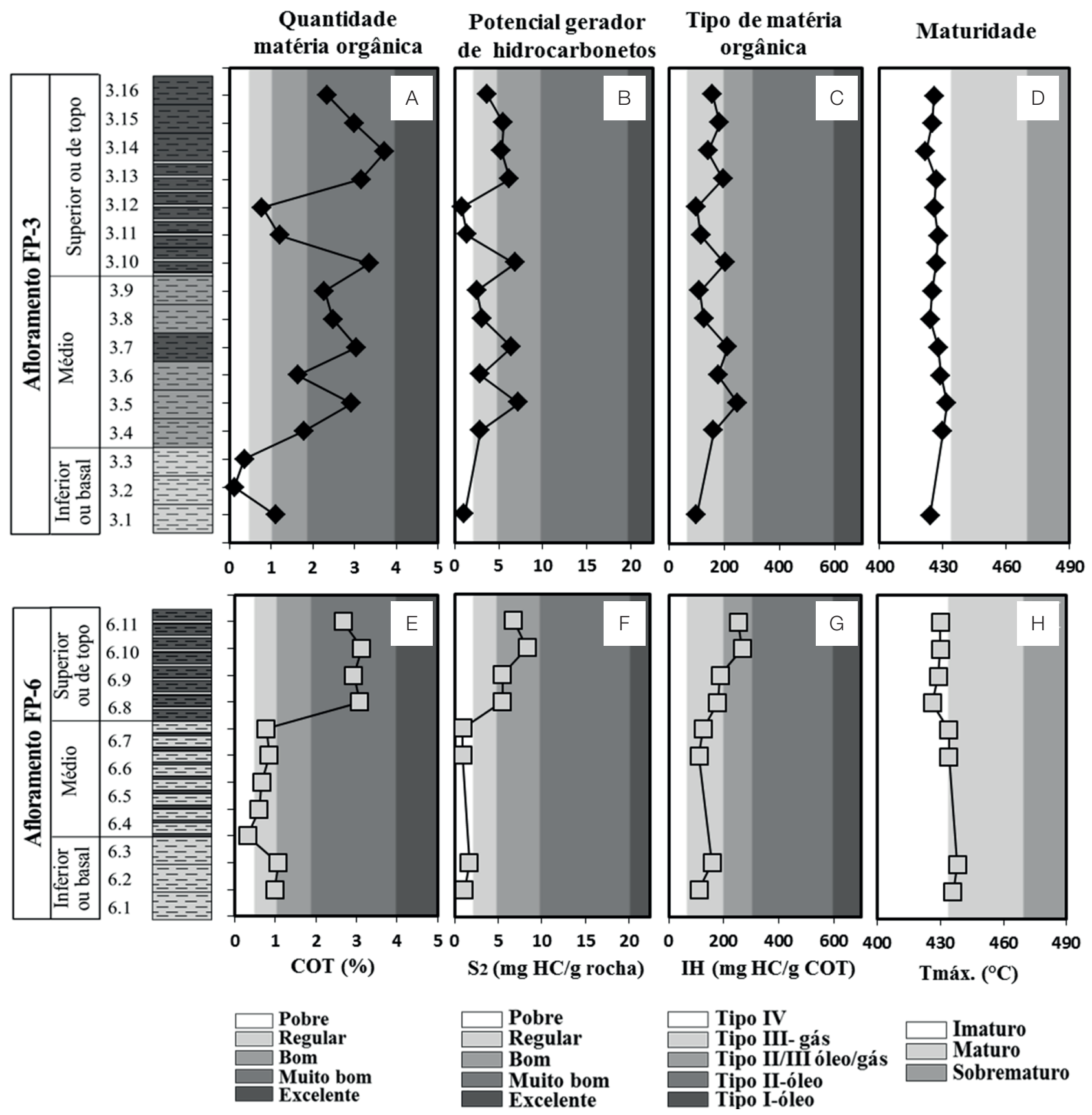

HC: hidrocarbonetos; COT: carbono orgânico total; $\mathrm{S}_{2}$ : potencial gerador de hidrocarbonetos; IH: índice de hidrogênio; Tmáx.: temperatura máxima de pirólise.

Figura 4. Perfil dos parâmetros carbono orgânico total, potencial gerador de hidrocarbonetos, índice de hidrogênio e temperatura máxima de pirólise para os afloramentos do FP-3 e FP-6 da Formação Pimenteiras da Bacia de Parnaíba, destacando-se com cor branca e tons de cinza os intervalos de classificação definidos por Peters e Cassa (1994). 
a geração de hidrocarbonetos (Figura 4A). Entretanto, as amostras 3.1, 3.4, 3.6 e 3.11, representando um percentual de $25 \%$, mostraram potencial bom. As amostras 3.2, $3.3 \mathrm{e}$ 3.12 oscilaram entre potencial regular e pobre. Na avaliação do potencial para as amostras de FP-6 por meio do gráfico de COT da Figura 4E, observou-se que aquelas localizadas no terço superior do afloramento, representando $36 \%$ das amostras do afloramento, possuem um potencial muito bom para gerar hidrocarbonetos. Enquanto, 64\% das amostras do afloramento, localizadas no terço basal a médio, apresentaram potencial entre regular e pobre.

Os resultados obtidos pela pirólise Rock Eval são comumente usados para indicar a qualidade da rocha geradora. Assim, o parâmetro $\mathrm{S}_{2}$ representa o potencial gerador e corresponde à quantidade de hidrocarbonetos liberados pelo querogênio (em mg $\mathrm{HC} / \mathrm{g}$ de rocha), o qual para o afloramento FP-3, oscilou desde $0,78 \mathrm{mg} \mathrm{HC} / \mathrm{g}$ de rocha para a amostra 3.12 até $7,28 \mathrm{mg} \mathrm{HC} / \mathrm{g}$ de rocha na amostra 3.5. Já para as amostras de FP-6, os valores estão no intervalo de $0,93 \mathrm{mg} \mathrm{HC} / \mathrm{g}$ de rocha para amostra 6.6 até $8,34 \mathrm{mg} \mathrm{HC} / \mathrm{g}$ de rocha para 6.10 (Tabela 2).

As amostras de rochas de FP-3 que apresentaram bom potencial gerador, ou seja, valores $\geq 5 \mathrm{mg} \mathrm{HC} / \mathrm{g}$ de rocha (Peters e Cassa, 1994) foram: 3.5, 3.7, 3.10, 3.13, $3.14 \mathrm{e}$ 3.15 , com valores de $\mathrm{S}_{2}$ entre 5,31 e $7,28 \mathrm{mg} \mathrm{HC} / \mathrm{g}$ de rocha (Figura 4B). No afloramento FP-6, as amostras localizadas no terço superior $(6.8,6.9,6.10$ e 6.11$)$ apresentaram altos valores de $\mathrm{S}_{2}$, entre 5,34 e $8,34 \mathrm{mg} \mathrm{HC} / \mathrm{g}$ de rocha (Figura 4F).

O tipo de matéria orgânica foi avaliado por meio dos valores propostos por Peters e Cassa (1994) para o IH. Conforme é mostrado nas Figuras $4 \mathrm{C}$ e $4 \mathrm{G}$, foi possível observar para ambos os afloramentos que as amostras apresentaram abundância do querogênio tipo III, sendo de 77 e $75 \%$ para as amostras de FP-3 e FP-6, respectivamente. Os percentuais restantes foram de querogênio tipo II/III, correspondentes ao potencial gerador de gás e mistura de óleo-gás, respectivamente. Por outro lado, nenhuma das amostras estudadas apresentou querogênio tipo I ou IV.

Igualmente, é possível avaliar o tipo de querogênio e o potencial de geração de hidrocarbonetos por meio do diagrama de $\mathrm{S}_{2}$ versus COT, segundo o reportado nos trabalhos de Dahl et al. (2004), Oliveira et al. (2006), Duarte et al. (2013) e Fakhri et al. (2013). De acordo com o representado na Figura 5, para os afloramentos FP-3 e FP-6, as amostras foram localizadas predominantemente na área do querogênio tipo III. No entanto, as amostras 3.5, 3.7, 3.10, $6.10 \mathrm{e}$ 6.11, que apresentaram elevados teores de COT, se mostraram acima da linha de $\mathrm{IH}=200$, indicando serem constituídas de querogênio do tipo II/III (Erik et al., 2006). Cabe destacar que o querogênio tipo II/III descreve uma composição de transição entre os tipos II e III, que comumente representa uma mistura de matéria orgânica marinha e terrestre.
O querogênio tipo III é derivado de matéria orgânica de origem terrestre ou lagos, sendo frequentemente encontrado em rochas depositadas em ambiente marinho deltaico e fácies marinhas óxicas (Peters et al., 2005).

Quanto à Tmáx. na qual ocorre o craqueamento do querogênio na pirólise, para o afloramento FP-3 (Figura 4D) foi sugerido um comportamento uniforme na faixa imatura (Tmáx. $<435^{\circ} \mathrm{C}$ ) em todas as amostras com valores entre 422 e $432^{\circ} \mathrm{C}$ (Tabela 2). Mesmo assim, no afloramento FP-6 as amostras do terço médio a superior apresentaram valores de 426 a $434^{\circ} \mathrm{C}$, indicando imaturidade termal. Entretanto, as duas primeiras amostras no terço inferior (6.1 e 6.2) evidenciaram temperaturas entre 436 e $438^{\circ} \mathrm{C}$, sugerindo o início da fase de maturação, possivelmente pelo efeito do soterramento, em razão dessas amostras estarem localizadas na base do afloramento (Tabela 2 e Figura 4H). De acordo com o índice de coloração de esporo realizado no afloramento FP-6 por Andrade et al. (2015), as amostras estão imaturas à geração de hidrocarbonetos.

\section{Paleoambiente deposicional}

A partir do diagrama IH versus COT é possível inferir a quantidade de matéria orgânica terrestre e o grau de oxigenação em condições subaquáticas para diferentes paleoambientes deposicionais (Routh et al., 1999). No presente estudo, a relação entre o IH e o COT pode ser verificada na Figura 6 para os afloramentos FP-3 e FP-6, com o intuito de mostrar as condições de sedimentação.

Observou-se uma correlação positiva entre IH e COT para as amostras de cada afloramento analisadas por pirólise Rock Eval - lembrando-se que essas amostras apresentaram COT $>0,8 \%$. Essa correlação entre IH e COT indica que o aumento deste está relacionado com uma riqueza

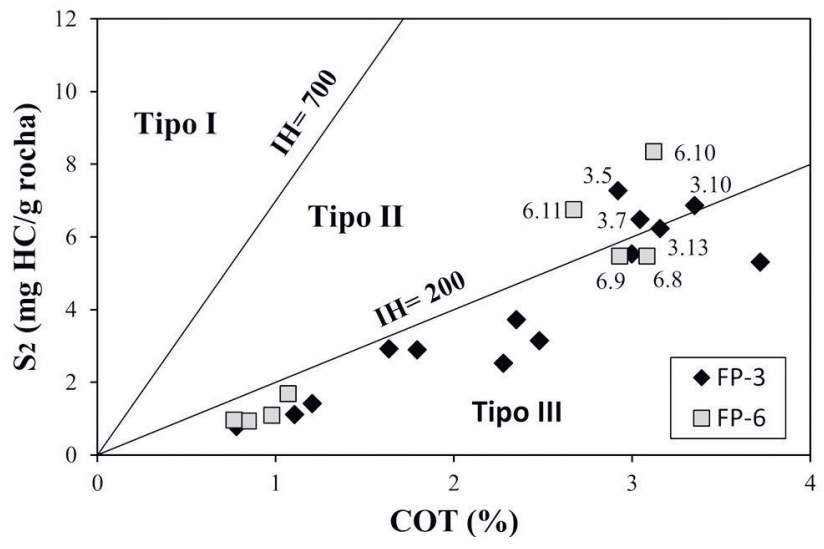

$\mathrm{S}_{2}$ : potencial gerador de hidrocarbonetos; $\mathrm{HC}$ : hidrocarbonetos; $\Vdash \mathrm{H}$ : índice de hidrogênio; COT: carbono orgânico total.

Figura 5. Diagrama de carbono orgânico total versus potencial gerador de hidrocarbonetos para as amostras de rocha dos afloramentos FP-3 e FP-6 da Formação Pimenteiras. 
em lipídeos, o que pode sugerir uma fonte marinha (Routh et al., 1999). Segundo um estudo de palinofácies realizado por Andrade et al. (2015) para o afloramento FP-6, as amostras localizadas no topo do afloramento (intervalo 6.8 a 6.11) contêm maiores concentrações de microplânton do que as amostras da porção basal e média do afloramento. Por conseguinte, as oscilações dos conteúdos de hidrogênio, oxigênio e COT para os dois afloramentos representam diferenças nas condições paleoambientais devidas às variações relativas do nível do mar ao longo da deposição da formação. Vários autores reportaram uma tendência similar no gráfico IH versus COT para sedimentos transgressivos e regressivos, como na Bacia San Juan, New Mexico (Pasley et al., 1991); na Formação Kazhdomi da Bacia de Zagros, Iran (Fakhri et al., 2013); e na Bacia Maamba Coalfield, Zambia (Robison e Engel, 1993).

A razão isotópica de carbono $\left(\delta^{13} \mathrm{C}\right)$ do extrato das rochas, junto com outros parâmetros geoquímicos, pode fornecer informação sobre a origem da matéria orgânica e paleoambiente deposional (Oliveira et al., 2006; Freiree Monteiro, 2013). Conforme pode ser observado na Tabela 2 para o afloramento FP-3, as composições isotópicas de carbono variaram entre $-25,54$ e $-27,86 \%$, enquanto as amostras de FP-6 exibiram valores de $-25,68$ a $-26,89 \%$. Na Figura 7 apresenta-se a variação de $\delta^{13} \mathrm{C}(\%)$ com relação ao COT para os afloramentos FP-3 e FP-6.

Foi observado, na Figura 7A, elevados valores de COT associados a valores menos negativos de $\delta^{13} \mathrm{C}$ para os intervalos de amostra de 3.5 a 3.10 e de 3.13 a 3.16 , sugerindo condições de deposição marinha relacionadas às inundações. Entretanto, as amostras 3.1, 3.2, 3.3, 3.4, 3.11 e 3.12, com valores $<2 \%$ de COT, apresentaram valores mais negativos de $\delta^{13} \mathrm{C}$, sugerindo condições deposicionais mais continentais. De acordo com Freire e Monteiro (2013), a matéria orgânica

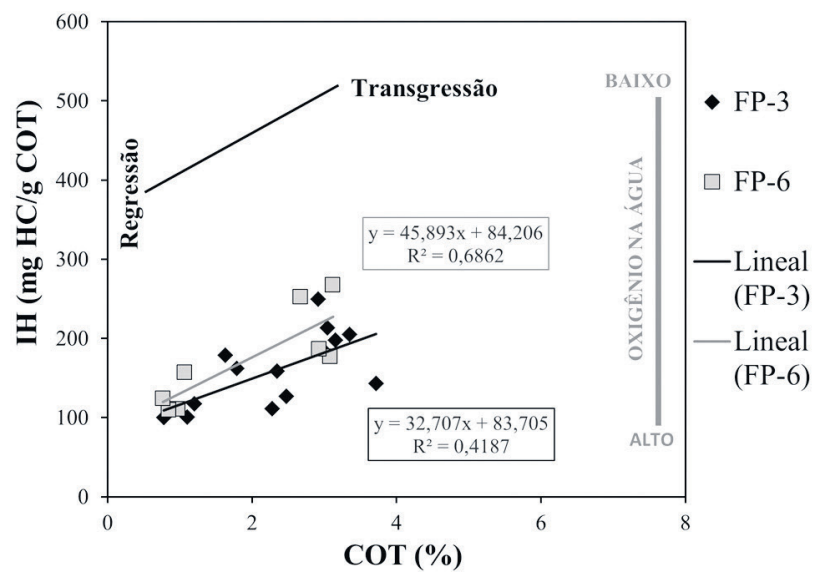

IH: índice de hidrogênio; HC: hidrocarbonetos; COT: carbono orgânico total.

Figura 6. Diagrama de teor do índice de hidrogênio versus carbono orgânico total para as amostras de rocha dos afloramentos FP-3 e FP-6 da Formação Pimenteiras. originada em ambiente marinho ou salino pode apresentar valores de $\delta^{13} \mathrm{C}$ menos negativos do que a proveniente de ambientes continentais da mesma idade.

Um comportamento interessante pode ser observado para o afloramento FP-6, no qual foi possível distinguir claramente dois grupos de amostras (Figura 7B). Um grupo está composto pelas amostras do terço inferior e médio no afloramento (intervalo de amostras 6.1 a 6.7), com valores de COT $<1,5 \%$, no qual foram observados valores de $\delta^{13} \mathrm{C}$ menos negativos (é dizer enriquecidas em ${ }^{12} \mathrm{C}$ ) para as amostras com baixos teores de COT, o que sugere um paleoambiente deposicional mais terrestre. Entretanto, o segundo grupo compreendido pelas amostras do terço superior (amostras 6.8 a 6.11), com valores de COT $>2,5 \%$ (rico em matéria orgânica), apresentou valores de $\delta^{13} \mathrm{C}$ menos negativos quando comparado com o primeiro grupo. Por conseguinte,
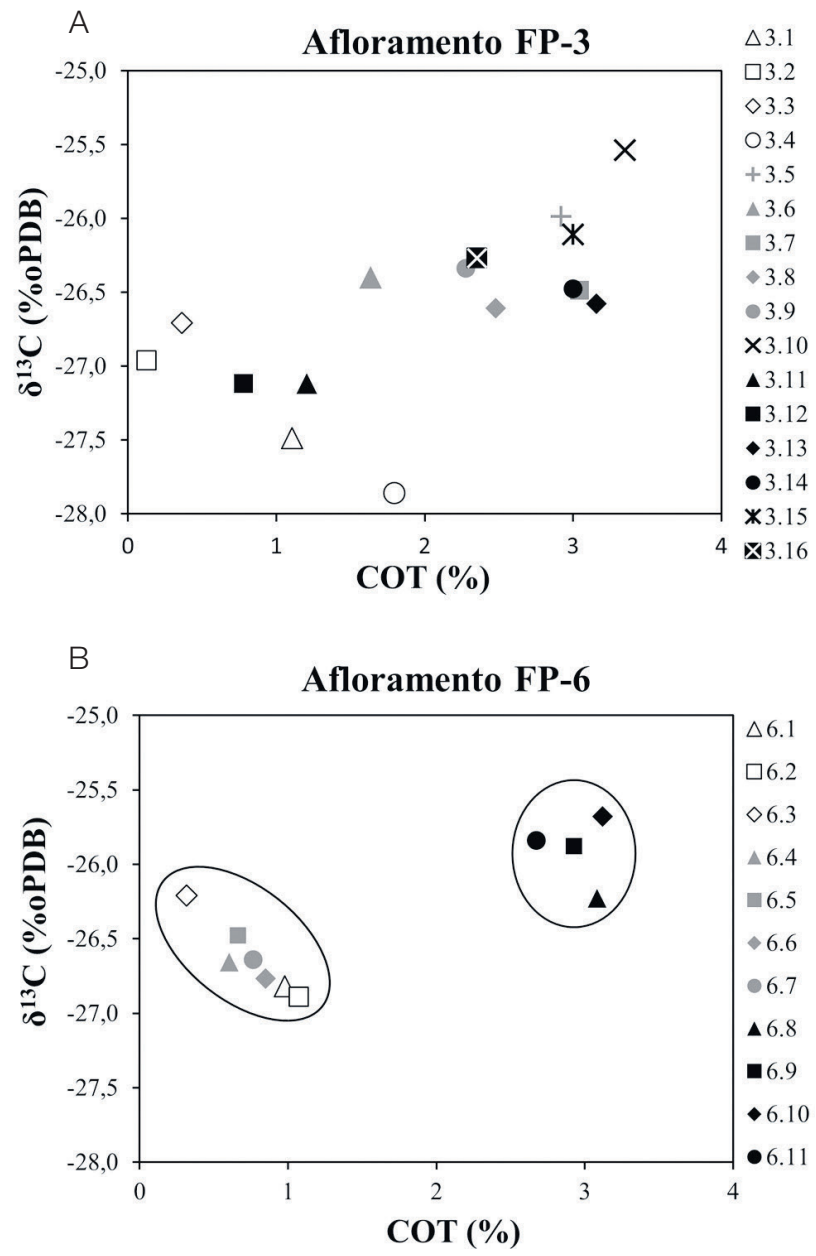

$\delta^{13} \mathrm{C}$ : composição de isótopos estáveis de carbono ${ }^{13} \mathrm{C} /{ }^{12} \mathrm{C}$; PDB: Pee Dee Belemnite, padrão internacional de carbonato (Belemnite fóssil) da Formação Pee Dee do Cretáceo Superior na Carolina do Sul, EUA; COT: carbono orgânico total.

Figura 7. Composição isotópica versus os teores de carbono orgânico para os afloramentos: (A) FP-3 e (B) FP-6. 
o paleoambiente deposicional dos folhelhos localizados no topo do afloramento seria marinho devido a uma subida relativa do mar na bacia. Esse fato foi corroborado pelo incremento de microplâncton reportado por Andrade et al. (2015) para essas amostras. Variações mais positivas de $\delta^{13} \mathrm{C}$ em ambientes marinhos têm sido correlacionadas a ciclos transgressivos ou eventos anóxicos, enquanto que variações negativas indicariam ciclos regressivos (Lamb et al., 2006, Freire e Monteiro, 2013).

\section{CONCLUSÕES}

Os principais parâmetros geoquímicos foram avaliados nas amostras de rocha em dois afloramentos da Formação Pimenteiras, na Bacia do Parnaíba. Para o afloramento FP-3, localizado no km 29 TO-010 no estado do Tocantins, estimou-se que $81 \%$ das amostras evidenciaram a quantidade mínima requerida para gerar hidrocarbonetos. O potencial gerador, avaliado pelo parâmetro $\mathrm{S}_{2}$, indicou um bom potencial gerador para amostras localizadas a 5, 7, 10, 13, 14 e 15 metros de altura medidos a partir da base no afloramento. Com base nos valores IH da matéria orgânica, $77 \%$ das amostras analisadas indicaram predominância do querogênio tipo III e $23 \%$ foram do tipo II/III, indicando mistura entre matéria orgânica terrestre e marinha. No afloramento FP-6, localizado no $\mathrm{km} 399$ da rodovia BR-153 (Belém-Brasília), no estado do Tocantins, foi evidenciado que $46 \%$ das amostras atingiram a quantidade mínima requerida para gerar hidrocarbonetos. O parâmetro $\mathrm{S}_{2}$ permitiu identificar, nas amostras coletadas no terço superior, um potencial bom para a geração de hidrocarbonetos. Os $75 \%$ das amostras analisadas indicaram querogênio tipo III, enquanto os $25 \%$ restantes evidenciaram querogênio tipo II/III, correspondente às duas últimas amostras no topo do afloramento.

De maneira geral, foi verificado, para o afloramento localizado no km 29 TO-010, que as amostras coletadas a 5, 7 e $10 \mathrm{~m}$ a partir da base do afloramento exibiram bom potencial para gerar óleo ou gás; e as coletadas entre 13 e $15 \mathrm{~m}$ medidos desde a base foram associadas ao potencial gerador de gás. Para o afloramento localizado no km 399 da BR-153 (Belém-Brasília), as amostras do terço superior apresentaram as melhores características para gerar hidrocarbonetos, no qual as duas primeiras amostras revelaram potencial gerador de gás e as duas últimas para gerar óleo ou gás.

A maturidade da matéria orgânica determinada por Tmáx. indicou que as amostras estão imaturas para a geração de hidrocarbonetos, sem efeitos térmicos importantes devido ao soterramento, como foi evidenciado nas amostras coletadas entre 1 e 2 metros de altura no afloramento FP-6.
Os resultados dos parâmetros geoquímicos permitiram a identificação de variações no paleoambiente deposicional dos afloramentos decorrentes de subidas relativas no nível do mar no Período Devoniano. Cabe ressaltar que os resultados deste trabalho, aliados aos obtidos por Andrade et al. (2015), corroboram que as amostras do terço superior do afloramento FP-6 correspondem a uma superfície de inundação máxima.

\section{AGRADECIMENTOS}

Agradecemos à Shell Brasil E\&P/UFBA (nº 1.255/2013) pelo apoio financeiro por meio do projeto Formação do Centro de Excelência em Geoquímica do Petróleo do Instituto de Geociências da UFBA(GEOQPETROL). Este estudo também contou com o apoio da Coordenação de Aperfeiçoamento de Pessoal de Nível Superior (CAPES), que concedeu a bolsa de estudos ao primeiro autor. Agradecemos também ao professor Jefferson Mortatti pelas análises de isótopos estáveis de carbono realizadas no Laboratório de Isótopos Estáveis do CENA/USP.

\section{REFERÊNCIAS}

Almeida, F. F. M., Carneiro, C. D. R. (2004). Inundações marinhas fanerozóicas no Brasil e recursos minerais associados. In: V. Mantesso-Neto, A. Bartorelli, C. D. R. Carneiro, B. B.Brito-Neves (Orgs.). Geologia da continente Sul-Americano: Evolução da obra de Fernando Flávio Marques de Almeida. São Paulo: Beca. p. 43-58.

Amaral, P. F., Hidalgo, R., Barbosa, R. C. M., Nogueira, A. C. R. (2013). Palinomorfos da Formação Pimenteiras (Devoniano): Contribuição na avaliação do potential de geração de petróleo da borda oeste da Bacia do Parnaíba, região de Pedro Afonso (TO). XIII Simpósio de Geologia da Amazônia, 111-113. Pará: SBG.

Andrade, C. L. N., Cardoso, T. R. M., Machado, A. J. (2015). Palinofácies de pelitos da Formação Pimenteiras (Devoniano), na borda oeste Bacia do Parnaíba, Brasil. XV Congresso Brasileiro de Geoquímica. Brasília: SBGq. Disponível em: $<$ http://www.sbgq.org.br/index.php?option=com_phocad ownload\&view=category\&id=98: geoquimica-organica $>$. Acesso em: 7 jun. 2015.

Araújo, D. B. D. (2015). Bacia do Parnaíba: sumário geológico e setores em oferta da décima terceira rodada de licitações. Disponível em: <http://www.brasil-rounds. gov.br/round_13/portugues_R13/setores.asp $>$. Acesso em: 15 jul. 2015. 
Berner, R. A. (1984). Sedimentary pyrite formation: an update. Geochimica et Cosmochimica Acta, 48(4)605-615.

Bizzi, L. A., Schobbenhaus, C., Vidotti, R. M., Gonçalves, J. H. (2003). Bacias Sedimentares Paleozóicas e MesoCenozóicas Interiores. Geologia, Tectônica e Recursos Minerais do Brasil, 55-85.

Carozzi, V. C., Falkenhein, F. U. H., Carneiro, R. G., Esteves, F. R., Contreiras, C. J. A. (1975). Análise ambiental e evolução tectônica sinsedimentar da seção siluro-eocarbonifera da bacia do Maranhão, v. 7, 89p. Ciência-Técnica-Petróleo, Seção Exploração de Petróleo. Petrobras: Rio de Janeiro.

Dahl, B., Bojesen-Koefoed, J., Holm, A., Justwan, H., Rasmussen, E., Thomsen, E. (2004). A new approach to interpreting Rock-Eval S2 and TOC data for kerogen quality assessment. Organic Geochemistry, 35(11), 1461-1477.

Della Fávera, J. C. (1990). Tempestitos da Bacia do Parnaíba: um ensaio holístico. Tese (Doutorado). Porto Alegre: Instituto de Geociências - UFRGS.

Della Fávera, J. C. (2001). Fundamentos de Estratigrafia Moderna. Rio de Janeiro: Editora da UERJ, 263p.

Della Fávera, J. C., Begossi, R., Medeiros, M. A. M. (2003). Prodelta Hummocky Cross-stratified Sandstone Lobes: a New Model for Brazilian Paleozoic Deltas. Latinamerican Congress of Sedimentology, 119-120. Belém: IAS.

Duarte, L. V., Silva, R. L., Mendonça Filho J. G. (2013). Variação do COT e pirólise Rock-Eval do Jurássico inferior da região de S. Pedro de Moel (Portugal). Potencial de geração de hidrocarbonetos. Comunicações Geológicas, 100 (Especial I), 107-111.

Erik, N. Y., Özçelik, O., Altunsoy, M. (2006). Interpreting Rock-Eval pyrolysis data using graphs of S2 vs. TOC: Middle Triassic-Lower Jurassic units, eastern part of SE Turkey. Journal of Petroleum Science and Engineering, 53(1), 34-46.

Fakhri, M., Tabatabei, H., Amiri, A. (2013). Comparing the potential of hydrocarbon generation of Kazhdomi and Pabdeh formations in Bangestan anticline (Zagros Basin) according to Rock-Eval pyrolysis Data. Journal of Earth Science and Climatic Change, 4(5), 2-7.

Freire, A. F. M., Monteiro, M. C. A. (2013). Novel approach for inferring the proportion of terrestrial organic matter input to marine sediments on the basis of TOC: TN and $\delta 13 \mathrm{C}$ org signatures. Scientific Research, 3(2), 74-92.
Lamb, A. L., Wilson, G. P., Leng, M. J. (2006). A review of coastal palaeoclimate and relative sea-level reconstructions using $\delta 13 \mathrm{C}$ and $\mathrm{C} / \mathrm{N}$ ratios in organic material. EarthScience Reviews, 75(1), 29-57.

Menezes, T. R., Mendonça Filho, J. G., Araújo, C. V., Souza, I. V. A. F., Mendonça, J. O. (2008). Fácies orgânica: conceitos, métodos e estudos de casos na indústria do petróleo. Brazilian Journal of Geology, 38(2), 80-96.

Oliveira, L. C., Rodrigues, R., Duarte, L. V., Lemos, V. B. (2006). Avaliação do potencial gerador de petróleo e interpretação paleoambiental com base em biomarcadores e isótopos estáveis do carbono da seção Pliensbaquiano-Toarciano inferior (Jurássico inferior) da região de Peniche (Bacia Lusitânica, Portugal). Boletim de Geociências da Petrobras, 14(2), 207-234.

Parra, C. J. O. (2012). Caracterização geoquímica através de biomarcadores de amostras de afloramentos da Formação Pimenteiras (Devoniano) da borda oeste da Bacia do Parnaíba. Dissertação (Mestrado). Rio de Janeiro: Universidade Estadual do Norte Fluminense Darcy Ribeiro.

Pasley, M. A., Gregory, W. A., Hart, G. F. (1991). Organic matter variations in transgressive and regressive shales. Organic geochemistry, 17(4), 483-509.

Peters, K. E., Cassa, M. R. (1994). Applied source rock geochemistry. In: L. B. Magoon, W. Dow (Eds.), The Petroleum System - From Source to Trap. Tulsa: American Association of Petroleum Geologists Memoir 60, p. 93-120.

Peters, K. E., Walters, C. C., Moldowan, J. M. (2005). The Biomarker Guide: biomarkers and isotopes in petroleum exploration and earth history. 2 ed. Cambrige: Cambrige University Press. v. 2.

Robison, V. D., Engel, M. H. (1993). Characterization of the source horizons within the late Cretaceous transgressive sequence of Egypt. Source Rocks in a Sequence Stratigraphic Framework. AAPG Studies in Geology, 37(1),101-117.

Rodrigues, R. (1995). A geoquímica orgânica da Bacia do Parnaiba. Tese (Doutorado). Porto Alegre: Instituto de Geociências - UFRGS.

Routh, J., Mcdonald, T. J., Grossman, E. L. (1999). Sedimentary organic matter sources and depositional environment in the Yegua formation (Brazos County, Texas). Organic Geochemistry, 30(11), 1437-1453.

Santos, M. E. C. M., Carvalho, M. S. S. (2009). Paleontologia das Bacias do Parnaíba, Grajaú e São Luís. Rio de Janeiro: CPRM Serviço Geológico do Brasil. 
Silva, S. M. O. A. (2005). Revisão sistemática de icnofósseis da Formação Pimenteira, Devoniano da bacia do Parnaíba, no Estado do Piauí. Tese (Doutorado). Rio de Janeiro: Universidade Federal do Rio de Janeiro.

Tissot, B., Welte, D. H. (1984). Petroleum formation and occurrence: a new approach to oil and gas exploration. 2. ed. New York: Heidelberg Springer Verlang.
Vaz, P. T., Rezende, N. G. A. M., Wanderley Filho, J. R., Travassos, W. A. S. (2007). Bacia do Parnaíba. Boletim de Geociencias da Petrobras, 15(2), 253-263.

Werne, J. P., Lyons, T. W., Hollander, D. J., Formolo, M. J., Damsté, J. S. S. (2003). Reduced sulfur in euxinic sediments of the Cariaco Basin: sulfur isotope constraints on organic sulfur formation. Chemical Geology, 195(1), 159-179. 